Volumen XX, número 1, enero-junio de 2020.

Recibido: 4 de diciembre de 2018.

Revista de Estudios

Transfronterizos

Aprobado: 28 de enero de 2020.

\title{
Élites tarapaqueñas y migrantes chilenos: criminalización, delitos y rebeldías en el Iquique peruano: 1870-1879*
}

\section{The ruling classes of Tarapacá and Chilean migrants: criminalization, crimes and rebellions in Peruvian Iquique: 1870-1879}

\author{
Damián Lo Chávez** \\ Universidad de Tarapacá, Arica, Chile.
}

\begin{abstract}
Resumen
Este trabajo explora una etapa temprana de la historia social de Iquique: los años previos a la Guerra del Pacífico y la última etapa de la soberanía peruana, período caracterizado por el crecimiento acelerado de la industria salitrera y del puerto de Iquique. En los años estudiados, la provincia recibió una gran cantidad de inmigrantes chilenos, principalmente peones de la zona central del país, quienes experimentaban una temprana fase de transición al trabajo asalariado. En la ciudad desplegaron múltiples formas de rebeldías contra el orden urbano de las élites tarapaqueñas. Estas últimas pretendían convertir a Iquique en una ciudad moderna, funcional a la acumulación de capital, para lo cual intentaron incrementar el control social sobre el espacio urbano y sus habitantes. Este artículo reivindica el conflicto social entre los sectores populares urbanos y las élites citadinas como un importante factor de desarrollo urbano. A través del estudio de fuentes primarias se hace una aproximación a la sociedad del período en cuestión, analizando las diversas
\end{abstract}

* Este trabajo es producto de una investigación realizada en el marco del Programa de Magíster en Historia de la Universidad de Tarapacá, UTA Mayor 5752/17, financiada por el proyecto FONDECYT $\mathrm{N}^{\mathrm{o}} 1171198$.

** Historiador, magíster en Historia, Universidad de Tarapacá. Docente de la Universidad de Tarapacá, Chile. Correo electrónico: damianernesto.lo@gmail.com

Cómo citar este artículo: Lo Chávez, D. (2020). Élites tarapaqueñas y migrantes chilenos: criminalización, delitos y rebeldías en el Iquique peruano: 1870-1879. Si Somos Americanos. Revista de Estudios Transfronterizos, 20(1), 78-102. doi: $10.4067 /$ S0719-09482020000100078 
variables que se articulan en torno al conflicto social y evaluando su impacto en la configuración de la ciudad.

Palabras clave: migraciones, rebeldías, élites.

\begin{abstract}
This article explores an early moment in the social history of Iquique: the years prior to the War of the Pacific and the last stage of Peruvian sovereignty, which was a period characterized by the vertiginous growth of the saltpetre (nitrate) industry and the port of Iquique. In the years studied, the province received a large number of Chilean migrants. These were mainly laborers from the central region of Chile who were experiencing an early phase of the labor transition towards salaried employment. In the city, they adopted various forms of rebelliousness against the urban order of the ruling classes of the province of Tarapaca. The latter had been aiming to convert Iquique into a modern city that could respond to the needs of capital accumulation, and for this purpose they had tried to increase their social control over the urban space and its inhabitants. This article underlines how the social conflict between popular urban sectors and city elites was an important factor in urban development. The study of primary sources offers a depiction of the society of the period in question and provides an opportunity to analyze the variables linked to the social conflict and their impact on the configuration of the city.
\end{abstract}

Keywords: migrations, rebellion, ruling classes.

\title{
Introducción
}

Diversos ciclos económicos han atraído a una gran cantidad de personas de todo el mundo a la ciudad de Iquique, constituyéndose esta en una sociedad multiétnica de complejo tejido social. Durante la segunda mitad del siglo XIX, Tarapacá e Iquique fueron el epicentro donde convergieron los procesos de transformación social y económica de dos países, Chile y Perú: industrialización, proletarización y modernización. Existe memoria escrita de chilenos avecindados en la ciudad antes de la guerra, personajes de élite; por ejemplo, aquellos que dieron origen a la Compañía de Bomberos "de Hachas, Ganchos y Escaleras" (Filgueira, 2015, pp. 101-102). Sin embargo, y considerando los aportes de Carlos Donoso (2003a, 2003b, 2004, 2007, 2011) y Julio Pinto (1998; Pinto y Ortega, 1990; Pinto y Valdivia, 1997) al estudio de la presencia chilena en Tarapacá, los sujetos populares y el impacto de su presencia en la historia urbana han quedado parcialmente olvidados. Por otra parte, la historia de la 
ciudad, disponible en la bibliografía regional, normalmente es tratada como anecdotarios que tienen como protagonistas a la élite de la ciudad.

El presente trabajo aborda una problemática que ha sido poco trabajada: el conflicto social urbano en el Iquique peruano y su repercusión en la administración de la ciudad en la década previa a la Guerra del Pacífico. Este conflicto tuvo entre sus principales protagonistas a un creciente número de inmigrantes chilenos, cuya cantidad se incrementó a partir de las obras ferroviarias y el acelerado crecimiento de la industria salitrera en la década de 1870. La propuesta aquí planteada reivindica un modelo de historia urbana desde abajo en un doble sentido: "en primer lugar, una historia espacializada de los desposeídos; en segundo, una historia de las calles que examina la problemática de la ciudad y las consiguientes respuestas sociopolíticas desde abajo y desde arriba" (Ealham, 2005, p. 17). Los actores sociales mencionados, élites y sectores populares urbanos, se constituyen en agentes de la urbanización, proceso en el cual el conflicto juega un rol fundamental: "su papel en la producción del espacio es fundamental, pues clases, fracciones y grupos de clases conforman los agentes de la producción espacial" (Lefebvre, 2013, p. 93).

La metodología empleada para abordar este problema de investigación ha sido principalmente la revisión y el análisis de fuentes primarias: documentos institucionales de época producidos por la extinta administración peruana de Tarapacá, la desaparecida Iglesia Católica dependiente del obispado de Arequipa y el poder judicial peruano. Los archivos emanados por las instituciones policiales y punitivas peruanas gozan de particular atención, en tanto nos permitieron acceder a "a muchas aristas de la sociedad, el espacio urbano o la cultura popular” (Caimari, 2015, p. 501).

\section{Iquique: una sociedad urbana de migrantes en procesos de larga duración}

En Chile, hacia mediados del siglo XIX, se ponían en movimiento masas de trabajadores de origen campesino, peones y gañanes sin oficio, hombres y mujeres jóvenes que no veían expectativas en las relaciones de producción del inquilinaje y las escasas oportunidades laborales que ofrecía el latifundio (Salazar, 2000). Destaca como el fenómeno social más importante del siglo XIX chileno (Bengoa, 1990). Fue el trasfondo de donde surgiría la clase trabajadora chilena y los sectores populares que ingresaron en la modernidad y el trabajo asalariado.

Estos sectores tuvieron múltiples facetas y un desarrollo histórico desigual. Se caracterizaron por dos experiencias en común: la pobreza y la dominación (Salazar y Pinto, 1999). Este peonaje pasó del campo a la marginalidad urbana sobreviviendo en toda clase de oficios. A veces obedeciendo, otras rebelándose o participando en el mundo ilícito del crimen y la prostitución. Este fenómeno fue común a toda América Latina durante el 
siglo XIX y tuvo un notable desarrollo en Chile a partir de 1840, contribuyendo al crecimiento de las principales ciudades del país, especialmente de Santiago y Valparaíso (Romero, 2007). Sin embargo, estos sectores no compartían los valores modernos de la élite gobernante: la disciplina laboral y la moral dominante, lo cual dio lugar a un largo proceso de adaptación, caracterizado por la dialéctica rebeldía-represión. Terminada la inestabilidad institucional en 1830, diversas voces de la élite chilena plantearon la necesidad de reprimir, controlar e inculcar valores de patriotismo, ciudadanía y trabajo a la masa de exsoldados desmovilizados y vagabundos salidos de los campos en los turbulentos años de la guerra de Independencia (Pinto y Valdivia, 2009).

Este control social se tradujo en la implementación de dispositivos represivos como cárceles y policías, instituciones higienistas como hospitales y lazaretos, ordenanzas administrativas, regulación del espacio y la propagación de instituciones afines al orden social. Existe una prolífera historiografía sobre este proceso de conflicto social en torno a la rebeldía y el disciplinamiento, entre la que destacan los trabajos de Julio Pinto (1998), Milton Godoy (2017), María Angélica Illanes (1990), Gabriel Salazar (2000) y de este con Pinto (1998).

El proceso de conflicto aludido se vivió a lo largo del territorio chileno en la medida que los peones se trasladaban hacia las principales ciudades del país y también hacia el Norte Chico, frontera anterior a la Guerra del Pacifico. La expansión de la minería en el desierto chileno incorporó al peonaje al trabajo asalariado, proceso que data de las postrimerías de la Colonia. Sin embargo, el primitivo sistema de trabajo artesanal en minas pequeñas de poca mecanización no constituyó la base material suficiente para una completa proletarización del sujeto popular (Pinto y Ortega, 1990). La masa humana trashumante pasó posteriormente al Antofagasta boliviano, atraída por el enganche de las guaneras, las explotaciones argentíferas y el salitre. Tal muchedumbre llegaría a constituir la mayoría de la población del litoral boliviano en vísperas de la guerra, donde desarrolló una conflictiva relación con las autoridades locales (Pinto y Valdivia, 1997).

En la Provincia Litoral y posterior Departamento de Tarapacá, en el sur del Perú, a comienzos de la década de 1870 tuvo lugar una revolución industrial en torno al salitre, suceso que formó parte de un proceso global. El aumento demográfico en los países industrializados, las migraciones campo-ciudad y los adelantos tecnológicos en transporte y comunicaciones fueron los rasgos más característicos de la "era del capital"(Hobsbawm, 1998). Estos fenómenos repercutían a su vez en el crecimiento de las ciudades latinoamericanas, tanto capitales, como puertos y cabezas de provincias (Scobie, 1991).

En este contexto, un conjunto de factores aceleró el crecimiento de la industria salitrera y de las exportaciones a través del puerto de Iquique: el ferrocarril, la decadencia del guano y los avances técnicos permitieron mayores volúmenes de producción. La revolución en la industria del salitre fue un proceso encadenado a otros fenómenos sociales. Pedro 
Gamboni introdujo en 1852 avances que tuvieron por resultado grandes instalaciones donde se aprovechaban caliches de menor ley (Crozier, 1997). Posteriormente, el sistema Shanks, desarrollado en la provincia por James Thomas Humberstone en 1875, consolidó las ciudades del desierto y la urbanización de la pampa (González, 2016). En los transportes, el ferrocarril de Iquique a La Noria, construido por los hermanos Montero e inaugurado en julio de 1871, permitió reducir costos, contribuyendo así a la rentabilidad del negocio salitrero y a superar las ineficientes caravanas de mulas (Donoso, 2011). En 1872, el salitre equiparó a la industria del guano en aportes al fisco peruano, año en el cual situamos el comienzo del ciclo de expansión del salitre, período que concluiría tras la Primera Guerra Mundial (González, 2014). El inicio de este ciclo industrial aceleró la llegada del peonaje chileno a Tarapacá, al ser insuficiente la mano de obra local. Los capitales salitreros enviaron agentes a Chile a "enganchar" la fuerza laboral que poblaría el desierto (González, 2002).

Por su parte, la oligarquía chilena debió observar con resignación cómo la principal fuerza de trabajo abandonaba el país en dirección a Bolivia, Perú y más allá, planteándose intentos vanos de retener a los trabajadores al interior de las fronteras nacionales (Godoy, 2003). Sería Tarapacá el escenario definitivo de la proletarización del peonaje por diversos factores: tecnología que permitía un extenso trabajo asalariado, la dificultad de retroceder al territorio de origen y la imposibilidad de sobrevivir en el desierto al margen del salario y las relaciones capitalistas de producción. "En Tarapacá, el trabajo proletario casi no tenía escapatoria" (Pinto, 1998, p. 45).

¿Fue sencillo este proceso formativo de las clases trabajadoras en Tarapacá? Las experiencias de vida compartidas en torno a la pobreza y la resistencia a la dominación configuraron identidades cambiantes que transitaron desde el desacato y la rebelión, pasando por el rechazo de la modernidad hasta su integración organizada en ella con discurso crítico y reivindicación militante. Tarapacá fue escenario de esta transición estudiada por autores clásicos de la nueva historia social chilena. Antes del movimiento obrero moderno, el descontento popular estallaba a través de revueltas mediadas por el alcohol y la violencia, carentes de programa y dirección orgánica (Grez, 2000).

El desarrollo de un territorio urbano densamente poblado en la pampa tuvo un correlato en el crecimiento del puerto de Iquique en la Provincia de Tarapacá, separada del Departamento de Moquegua como unidad territorial administrativa en diciembre de 1868. Durante el período colonial, Tarapacá fue el territorio más austral del Virreinato del Perú. El pequeño caserío de Iquique no tuvo mayor relevancia. Sus habitantes, una pequeña población multiétnica, se dedicaban a la pesca para las minas de Huantajaya, a la extracción de guano y a labores portuarias menores. El centro administrativo se ubicaba al interior, en San Lorenzo de Tarapacá. La independencia del Perú sorprendió a Iquique sin mayores cambios en su fisonomía. Se trataba de una aldea sin planificación ni edificios públicos de importancia, como coinciden todas las descripciones del poblado 
que se refieren al tiempo que va de la Colonia tardía a la temprana república peruana (González y Bravo, 1994).

Entre 1828 y 1830 comenzaron las primeras exportaciones salitreras autorizadas por el Gobierno peruano a través del puerto de Iquique. Desde entonces, la aldea se expandió y albergó a una creciente sociedad, compuesta por elementos de diversa procedencia y ocupación, incluida su población flotante. El desarrollo comercial y el aumento demográfico generaron la necesidad de nuevas infraestructuras. En medio de catástrofes naturales y sanitarias, el poblado se transformó en una ciudad con hospital, alumbrado público, servicios de aseo, cuerpos policiales, aduanas, edificios públicos y una compleja administración urbana, gestionada en general por privados y con escaso apoyo del inestable Estado central (Donoso, 2007).

La demanda de brazos en las faenas portuarias, el comercio y las industrias urbanas atrajeron al puerto de Iquique a contingentes de trabajadores. Estos desarrollaron estrategias de supervivencia y múltiples conflictos con las élites residentes y autoridades del puerto. Surgió entonces la problemática de la adaptación a la modernidad urbana, la moral dominante y la disciplina laboral, pero en suelo peruano. La historiografía que ha abordado el fenómeno del surgimiento del peonaje, sus migraciones y proletarización ha señalado en diversas ocasiones el mayor peso numérico del componente masculino en esta masa en movimiento. Sin embargo, también numerosas mujeres llegaron a la ciudad junto con los peones. Sujetos populares masculinos y femeninos compartieron en el espaciotiempo experiencias, relaciones y vivencias cotidianas, articulando identidades que configuraron a la clase trabajadora en un contexto histórico definido (Thompson, 1989). Este artículo pretende relevar la dimensión urbana del conflicto social asociado a la temprana proletarización del peonaje que se insertó en los ranchos y callejones de la ciudad para conformar sectores populares urbanos: un sujeto histórico complejo, a veces marginal y a veces parcialmente integrado, multifuncional y polifacético (Romero, 1990).

Perú atravesó un complejo proceso político durante la década de 1870. Fue un período marcado por una burguesía emergente y por su proyecto modernizador, orientado al desarrollo de la economía exportadora, la reforma política y la superación de la dependencia del guano que ya estaba en declive (Mc Evoy, 1994). Implementado bajo la presidencia del presidente Manuel Pardo y Lavalle, este proyecto tuvo como uno de sus objetivos centrales controlar el salitre tarapaqueño a través de la polémica intervención fiscal en la industria (González, 2012). El Gobierno también creó nuevos cuerpos policiales y extendió la presencia estatal en la Provincia Litoral.

El volumen y la diversidad de origen de las migraciones en esta etapa previa a la guerra pueden observarse cuantitativamente basándose en diversas fuentes: el censo oficial de 1876, los registros de defunciones del Archivo del Obispado de Iquique y las estadísticas de partes de detenciones de la policía peruana. La siguiente tabla $\mathrm{N}^{\circ} 1$ corresponde a una evolución demográfica de Iquique en el tiempo, considerando diversas fuentes: 
Tabla $N^{\circ}$ 1: Población de Iquique entre 1814 y 1876

\begin{tabular}{cc}
\hline Año & Población \\
\hline 1814 & 300 \\
\hline 1845 & 797 \\
\hline 1866 & 3.249 \\
\hline 1876 & 11.717 \\
\hline
\end{tabular}

Fuente: Recuento de población de Tarapacá hacia 1814 (Archivo Histórico de Límites, sin título ni fojas, Ministerio de Relaciones Exteriores del Perú. Tap. 001).

La llegada masiva del peón carrilano chileno a territorio peruano fue un fenómeno migratorio altamente considerable según las cifras: se estiman decenas de miles de peones chilenos en distintos puntos del Perú. La construcción del ferrocarril durante el Gobierno del presidente José Balta, a comienzos de 1870, dio lugar a un acelerado crecimiento demográfico en el puerto y en la provincia. La ciudad adquirió una composición demográfica de Company Town con una mayoría de población masculina: un $70 \%$ hacia 1876. El censo de ese mismo año consigna 38.225 habitantes, distribuidos en 34 nacionalidades. Los chilenos representan un $64 \%$ de la población, 24.460 individuos, divididos en 14.395 hombres y 10.065 mujeres. En contraste, se registraron 17.018 peruanos, un 44,5\% del total. Año a año fue aumentando el excedente de nacimientos respecto de defunciones, en su mayoría hijos naturales de madres solteras, revelando relaciones informales que prevalecieron en el mundo popular (Tabla $\mathrm{N}^{\circ} 2$ ):

Tabla $N^{\circ}$ 2: Bautismos según legitimidad y contraste con defunciones (1870-1875)

\begin{tabular}{cccccc}
\hline Año & Legítimos & Naturales & Total & Defunciones & Excedente \\
\hline 1870 & 128 & 171 & 299 & 124 & 175 \\
\hline 1871 & 130 & 172 & 292 & 112 & 180 \\
\hline 1872 & 253 & 268 & 522 & 183 & 339 \\
\hline 1873 & 346 & 400 & 746 & 489 & 257 \\
\hline 1874 & 315 & 398 & 714 & 333 & 381 \\
\hline 1875 & 393 & 498 & 891 & 437 & 454 \\
\hline
\end{tabular}

Fuente: elaboración propia basada en Archivo del Obispado de Iquique (1857-1875). 
El predominio de los chilenos respecto del total de la población extranjera puede graficarse en varias fuentes documentales del período. Las defunciones registradas en el Archivo del Obispado de Iquique para el quinquenio 1870-1875 son un ejemplo de lo señalado. Hemos querido distinguir también los casos de personas originarias de Iquique, de la provincia y del resto del Perú (Tabla N³):

Tabla $N^{\circ}$ 3: Entierros según origen (1870-1875)

\begin{tabular}{cccccccc}
\hline Año & Chile & Iquique & Tarapacá & Perú & Bolivia & Argentina & $\begin{array}{c}\text { Otros } \\
\text { América }\end{array}$ \\
\hline 1870 & 21 & 34 & 17 & 20 & 23 & 1 & 0 \\
\hline 1871 & 31 & 18 & 17 & 16 & 16 & 1 & 2 \\
\hline 1872 & 69 & 29 & 18 & 29 & 22 & 2 & 0 \\
\hline 1873 & 192 & 58 & 31 & 77 & 31 & 2 & 2 \\
\hline 1874 & 104 & 49 & 23 & 48 & 32 & 4 & 1 \\
\hline 1875 & 115 & 79 & 29 & 50 & 44 & 5 & 4 \\
\hline Totales & 532 & 267 & 135 & 240 & 168 & 15 & 9 \\
\hline
\end{tabular}

Fuente: elaboración propia basada en Archivo del Obispado de Iquique (1857-1875).

La relación clase-nación puede observarse en los partes de detenciones de la Guardia Civil durante el año 1874. Si bien hubo chilenos integrantes de las élites regionales y trabajadores calificados y artesanos, la mayoría de las personas de esta nacionalidad se ocuparon en trabajos de baja calificación: jornaleros, cargadores, lancheros, carreteros y otros. Una característica de la temprana clase obrera en formación es precisamente la amplia gama de labores en la que participó. Distribuimos en cuadros diferentes los casos de ambos sexos, observándose tanto similitudes como tendencias propias la construcción social de cada género. La clasificación completa de los individuos detenidos en dicho año por oficio y nacionalidad, nos permite observar la relación de dichas variables y el peso de cada una en el conjunto de la sociedad del período (Tabla $\mathrm{N}^{\circ} 4$ ): 


\section{Tabla $N^{\circ}$ 4: Delitos masculinos según nacionalidad y oficio en el} segundo semestre de 1874

\begin{tabular}{ccccccccc}
\hline Delitos 1874 & Chilenos & Peruanos & Bolivianos & Argentinos & Europeos & Asiáticos & Otros & Total \\
\hline Trabajadores & 152 & 38 & 7 & 4 & 13 & 0 & 2 & 216 \\
\hline Marinos & 6 & 1 & 1 & 0 & 6 & 0 & 2 & 16 \\
\hline Arrieros & 9 & 12 & 6 & 8 & 0 & 0 & 0 & 35 \\
\hline Vendedores & 8 & 1 & 0 & 0 & 0 & 1 & 0 & 10 \\
\hline $\begin{array}{c}\text { Servicio } \\
\text { doméstico }\end{array}$ & 3 & 4 & 1 & 0 & 0 & 0 & 0 & 8 \\
\hline Comerciantes & 27 & 8 & 3 & 0 & 12 & 6 & 0 & 56 \\
\hline Profesión & 1 & 3 & 0 & 0 & 5 & 0 & 1 & 10 \\
\hline Empleados & 13 & 8 & 1 & 4 & 4 & 0 & 0 & 30 \\
\hline Oficios & 96 & 38 & 37 & 4 & 18 & 4 & 5 & 202 \\
\hline No conocido & 13 & 6 & 6 & 0 & 1 & 2 & 0 & 28 \\
\hline Militares & 0 & 6 & 0 & 0 & 0 & 0 & 1 & 7 \\
\hline Subtotales & 328 & 125 & 62 & 20 & 59 & 13 & 11 & 618 \\
\hline
\end{tabular}

Fuente: elaboración propia basada en partes diarios de la policía de la época (FPT, vol. 125).

Por último, la presencia femenina en la migración peonal chilena es un elemento que no puede dejar de tenerse en cuenta. Estudios clásicos del peonaje y la transición laboral, como los ya citados de Salazar (2000) e Illanes (1990), nos hablan de una dimensión femenina de este proceso. Las mujeres integraron los sectores populares, estableciendo relaciones informales en espacios de sociabilidad reñidos con la moral dominante. Hemos detectado modos de vida asociados a la chingana, la fonda, la pequeña empresa popular que reproduce la vida campesina y, a veces, la prostitución. Se configuraban así, desde el mundo popular, realidades contrapuestas al ideal de mujer de élite.

En la década de 1870, Iquique fue un escenario en el que podemos observar las dinámicas históricas de la compleja construcción social de las identidades de género en los sectores populares (Brito, 2005). Ejemplos conocidos de estos casos fueron las cantineras del 
ejército chileno, recordadas por la memoria oficial, oligárquica y masculina, en tanto sirvieron a la gloria militar de la república (Larraín, 2002). En estos casos se advierte que la mujer chilena, de origen peonal, pobló las periferias marginales de las ciudades, dedicándose a oficios propios de su sexo: sirvienta y costurera. Estos reflejan experiencias individuales dentro de procesos históricos de mayor alcance. El sentido de la aventura, del probar fortuna más allá de las fronteras, no fue un fenómeno únicamente masculino, y sin lugar a dudas el floreciente puerto de Iquique se alzó como un destino elegido por mujeres de sectores populares enfrentadas a circunstancias diversas. El principal componente de este mundo femenino popular fueron las lavanderas de origen chileno (Tabla $\mathrm{N}^{\circ} 5$ ).

\section{Tabla $N^{\circ}$ 5: Delitos femeninos según nacionalidad y oficio durante el segundo semestre de 1874}

\begin{tabular}{ccccccc}
\hline Mujeres & Chile & Perú & Bolivia & otras & Argentina & Totales \\
\hline Cocineras & 1 & 1 & 2 & 0 & 0 & 4 \\
\hline Lavanderas & 32 & 5 & 1 & 1 & 2 & 41 \\
\hline Textiles & 20 & 2 & 5 & 1 & 1 & 29 \\
\hline Comercio-local & 4 & 1 & 0 & 0 & 0 & 5 \\
\hline Bailarinas & 3 & 0 & 0 & 0 & 0 & 3 \\
\hline $\begin{array}{c}\text { Servicio } \\
\text { doméstico }\end{array}$ & 1 & 0 & 0 & 0 & 0 & 1 \\
\hline Otro/No tiene & 6 & 0 & 0 & 0 & 0 & 6 \\
\hline Subtotales & 67 & 9 & 8 & 2 & 3 & 89 \\
\hline
\end{tabular}

Fuente: elaboración propia basada en partes diarios de policía de la época (FPT, vol. 125).

No existe un registro exacto de la población de Iquique para el año 1874. Tampoco fue posible localizar partidas de detenciones correspondientes específicamente al año censal de 1876. El estudio de las décadas peruanas en Tarapacá reviste una serie de dificultades metodológicas, particularmente en lo que refiere a la documentación disponible. La dispersión geográfica de las fuentes y las vicisitudes históricas que han experimentado los documentos administrativos del período dificultan establecer secuencias continuas para cada año. Sin embargo, nos parece que los datos demográficos generales y los datos policiales expuestos permiten aproximarnos a las dinámicas de nación, clase y conflicto en los años abordados. 


\section{2. Élites regionales y administración de la ciudad de Iquique en la década de 1870}

¿Cómo estaba compuesta la élite en el Iquique de la década de 1870? ¿Cómo se vinculaba esta élite con la administración urbana de la ciudad de Iquique? Estaba integrada por varios segmentos interrelacionados entre sí, cuyo eje articulador fue la propiedad salitrera. Hablamos de élites regionales autóctonas, descendientes de los conquistadores españoles que fundaron los principales centros poblados del interior de la provincia, unidas en mestizaje con familias dirigentes de los grupos indígenas durante el período de contacto. En un principio vinculadas a la minería argentífera colonial, y posteriormente a la industria del salitre. Otro grupo correspondía al de los empresarios extranjeros, chilenos y europeos únicamente, que entre las décadas de 1830 y 1870 fueron, según hemos mencionado, responsables del temprano despegue de la industria salitrera. Entre estos dos grupos, las elites peruanas de Tarapacá y el empresariado extranjero, hubo matrimonios que generaron una comunidad de intereses políticos y de clase, que se expresaron a través de la participación directa e indirecta en los organismos administrativos regionales.

Otro segmento de la élite fue aquel que, si bien no tenía un control directo sobre los medios de producción, sí gozaba de poder político o influencia, como el prefecto, el subprefecto y los comandantes de Gendarmería y Guardia Civil, normalmente oficiales de ejército o armada. Por último, estaba el personal técnico: médicos, ingenieros y otros que prestaron diversas funciones en la administración pública y compartían la ideología y visión de mundo del empresariado: el proyecto moderno del capitalismo, la disciplina social y el orden urbano. Eran los propietarios del capital cultural, vinculados a los propietarios de las otras categorías de capital, según la interpretación de Bourdieu (2001). Se configuraba así un grupo dominante, la élite, amplio y complejo. Una versión, a escala regional, de aquella "minoría del poder" económico, político y militar-represivo (Wright Mills, 1987).

Un ejemplo clarificador de la conjunción de poder económico con administración pública fue la constitución del Honorable Concejo Departamental de la Provincia Litoral de Tarapacá en enero de 1876, de acuerdo con la Ley de Municipalidades de 1873. Este organismo funcionó en Tarapacá, hasta trasladarse al puerto al ratificar el Gobierno la condición de Iquique como capital de la provincia en febrero de 1875 (Donoso, 2007). Los organismos públicos de la provincia, Concejo Provincial, Concejo Departamental y Prefectura, se caracterizaron por una serie de disputas entre ellos, devenidas de la falta de fondos, el conflicto de interés y la confusión de competencias. Constan casos en que figuran los mismos individuos como propietarios salitreros, mineros y miembros de la administración pública, o bien, con evidentes parentescos entre autoridades, empresarios salitreros y familias de la élite regional. El Concejo Departamental estaba constituido por una directiva y un cuerpo técnico electo para encargarse de diversas inspecciones: 
tesorería, rectificación de calles, cuerpos de policías y prisiones, higiene y vacuna, etc., y un cuerpo de concejales que votaba y discutía propuestas.

La nómina del primer Concejo Departamental incluye a personajes de interés, como Antonio Gutiérrez de la Fuente, presidente del Concejo, ${ }^{1}$ hombre de primera relevancia en la historia política peruana. Natural de Huantajaya, nacido en las postrimerías de la Colonia, fue nieto del minero José Basilio de la Fuente Haro y Loayza, el hombre más rico y poderoso del Corregimiento de Tarapacá durante parte importante del siglo XVIII (Villalobos, 1979). Gutiérrez de la Fuente, miembro de una familia de larga tradición minera, llegó a ser Director Supremo de la República del Perú en 1829. Figura, hacia 1872, en la nómina de capitales salitreros de la provincia (Billinghurst, 1889). Debido a su edad y estado de salud, solía ausentarse de las reuniones del Concejo, instancias en que era reemplazado por el primer vicepresidente Juan José Azcárraga y un segundo vicepresidente, Eugenio Marquesado. Este último era primo del expresidente de la república, el tarapaqueño Ramón Catilla y Marquesado, miembro de una de las familias más ricas de la provincia, propietario de estacas y de la oficina San Carlos (Billinghurst, 1889). Catilla y Marquesado estaba casado con Grimanesa Loayza, quien pertenecía a una familia de origen colonial en la que figuraban al menos dos propietarios salitreros: Virginia Loayza, hermana de Grimanesa, y Juan Manuel de Loayza, primo de la susodicha (Torres, 2017).

Durante los primeros meses de 1876, se incorporaron nuevos concejales vinculados a la industria y los negocios: Sergio Digoy, ${ }^{2}$ Julián Gamboni -hijo del fallecido industrial Pedro Gamboni- y el empresario Carlos Lafrentz. Junto con estos personajes, dueños del capital, existen cargos de índole técnico-administrativa, propuestos y aprobados por el Concejo. El médico titular de la ciudad entre 1871 y 1876, José Arturo Ego-Aguirre, asumió como secretario de Higiene y Vacuna. Por otro lado, sin ser miembros del Concejo, este organismo contrató a los ingenieros Arza y Pflucker, de quienes se dice en las actas del Concejo Departamental que levantaron planos de la ciudad que incluían el proyecto de rectificar y ensanchar las calles incendiadas en octubre de $1875 .^{3}$

La contradicción de intereses entre la burguesía civilista de Lima y los empresarios tarapaqueños, el relativo aislamiento de Tarapacá del resto del Perú y la tenue presencia fiscal no necesariamente se tradujeron en nihilismo nacional ni en carencia de lealtad al

1 Gutiérrez de la Fuente juró y tomo posesión de su cargo el 24 de ese enero de 1876 (Archivo Nacional, Fondo de la Intendencia de Tarapacá, en adelante ARNIT, Vol. 592, p. 30).

2 Hijo de Bernardo Digoy, químico francés que instaló las primeras máquinas desalinizadoras de agua en Iquique en la década de 1840.

3 Compartimos lo señalado por Carlos Donoso en esta materia: existen documentos alusivos a al menos un plano oficial de la ciudad en 1871; sin embargo, dichos planos no han sido localizados. Los planos de Pfluckery Arza vendrían estando en la misma situación. Hacia 1874 apareció Pflucker y Cia. como propietarios de la oficina de máquina Santa Ana, con una capacidad productiva de 300 mil quintales españoles de salitre al año (Billinghurst, 1889). El debate en torno a la ampliación de calles en relación a ambos planos consta en ARNIT (Vol. 592, pp.88-91). 
Perú en tanto Estado-nación. El mejor ejemplo fue Alfonso Ugarte y Vernal, empresario salitrero, que junto con el también miembro del Concejo Departamental, Benigno Ceballos, tenían una sociedad salitrera que exportaba desde Caleta Molle. ${ }^{4}$ Alcalde en 1876 del Concejo Provincial que administraba la ciudad de Iquique, sirvió como voluntario con grado de coronel en la guerra. Lideró, organizó y financió un batallón de 426 soldados y 36 oficiales, muchos de ellos artesanos voluntarios de Iquique. Falleció en la defensa del Morro de Arica en circunstancias que lo transformaron en héroe del relato nacionalista peruano. Además de Ugarte, entre los oficiales y financistas del batallón figuraban otros salitreros tarapaqueños, como Estanislao Granadino, quien cedió bodegas salitreras y una casa de dos pisos en Iquique para uso del cuerpo. El Estado peruano los proveyó únicamente de fusiles y municiones, corriendo todo lo demás -uniformes, caballos y víveres- por cuenta de la élite peruana regional. Esta dinámica de servicio público e intereses empresariales entrañaba dificultades y falencias, propias de una burocracia administrativa no-profesional ni a tiempo completo. El Concejo Departamental debía resolver en reiteradas ocasiones los problemas de la administración del puerto, en tanto era frecuente la ausencia de Ugarte de su cargo como alcalde del Concejo Provincial, dejando dicho organismo acéfalo. ${ }^{5}$ Por otro lado, al ser los miembros de la administración propietarios de los principales inmuebles de la ciudad, muchas veces las deliberaciones del Concejo Departamental y Provincial devenían en recusaciones de conflicto de interés. Notorio es cómo Julián Gamboni y otros concejales debían abstenerse de deliberar y votar sobre la rectificación y ensanche de calles en 1876, por ser propietarios de inmuebles comprometidos (ARNIT, vol. 592, p. 90).

En septiembre de 1876, al tomar conocimiento del negociado entre el fisco peruano y Henry Meiggs para monopolizar y explotar el salitre del Toco en la vecina provincia de Antofagasta, el Concejo Departamental envió una misiva al Gobierno y al Congreso pidiendo anular dicho contrato (González, 2016). Anticipándose más de medio siglo al escenario de 1930, la élite regional argumentó que un posible fin de la industria salitrera tarapaqueña traería a la provincia la quiebra económica privada, la ruina de las arcas departamentales y el consiguiente despoblamiento de Iquique y Tarapacá (ARNIT, vol. 592, pp.150-154). La propiedad de comercio, industrias urbanas y oficinas salitreras por parte de las mismas firmas fue una de las principales características de la economía regional durante el ciclo expansivo. En vista de esta situación, los empresarios residentes en la ciudad pidieron una rebaja de las matrículas industriales, que se cobraron en un principio por cada establecimiento. Esta rebaja les fue concedida, en consideración de la crisis suscitada por la "devastadora" ley de expropiación del salitre y otras calamidades como el terremoto y maremoto de mayo de 1877 (Fondo de la Prefectura de Tarapacá [en adelante FPT], vol. 79). Los intereses de clase en torno a la industria salitrera eran

4 Sociedad propietaria de la oficina San Lorenzo, con capacidad anual de 300 mil quintales diarios de salitre. (Billinghurst, 1889).

5 La polémica en torno al abandono del cargo por parte de Ugarte en ARNIT (vol. 592, pp.123-129). 
debatidos en las mismas instancias y por los mismos personajes que decidían la administración urbana de la ciudad.

El primer secretario de este concejo, encargado de llevar las actas desde el primer mes de su constitución, fue un joven hijo de un próspero comerciante argentino, exiliado en el sur del Perú por la dictadura de Rosas: Guillermo Billinghurst Angulo (ARNIT, vol. 592, pp.7-9). Protagonista de la historia de la ciudad, de la provincia y de la historia política de ambos países, Billinghurst Angulo fue heredero de cierta fortuna familiar, por lo que invirtió en varios rubros, entre ellos el salitre. Además, fue investigador, escritor y periodista, llegando a ser alcalde de Lima en 1909 y presidente del Perú en 1912 (González, 2000).

\section{Los inmigrantes chilenos y el conflicto social}

La presencia de chilenos no fue un fenómeno nuevo en la década de 1870. Tampoco lo eran sus rebeldías que han sido notablemente trabajadas por Pinto (1998), particularmente aquellas que tuvieron como escenario la pampa salitrera. En las décadas anteriores a 1870, las autoridades peruanas habían temido la posibilidad de desórdenes o participación en movimientos sediciosos por parte de las primeras oleadas de peones llegados a la provincia. Sin embargo, la magnitud real de la presencia chilena no sería tan masiva ni su crecimiento tan acelerado hasta la década de 1870. Ese año, el prefecto Miguel ValleRiestra envió un informe al Ministerio de Gobierno, Policía y Obras Públicas, en el que sintetizaba las necesidades más urgentes de la provincia: reconstruir iglesias, obras para evitar desbordes de ríos y cárceles. Respecto de estas últimas, urgentes e indispensables, especialmente en Iquique y Pisagua, señalaba:

lugares que hoy son el centro, cada uno de cuatro a seis mil trabajadores, no de las mejores costumbres en jeneral, y que por tanto han de menester un lugar adecuado de retención y castigo para el orden y la moralidad. (Registro Oficial, 27 de enero de 1870 , s. p.)

Para la élite residente era complejo lidiar con las masas peonales que migraban al territorio tarapaqueño. No solo la violencia o la criminalidad eran permanentes fuentes de conflicto entre ambos sectores sociales, también la moralidad pública. En marzo de 1875, el prefecto Amaro Tizón comunicaba al comandante de la Guardia Civil:

Ha llegado a mi noticia que en los sitios más públicos a donde afluye, con el objeto de tomar baños, un considerable número de personas, se presentan algunos hombres del bajo pueblo completamente desnudos y no pocas mujeres casi en el mismo estado. Como no se ocultará a Ud. la gravísima falta en que incurren los que así proceden, creo necesario prevenir a Ud. que en la esfera de sus atribuciones, haga perseguir, aprehender y castigar a los que se manifiesten del 
modo más escandaloso en abierta pugna con las buenas costumbres y con las leyes ineludibles de la moral social. (FPT, vol. 16, f. 304, 1875)

Esta comunicación contiene algunos elementos que son claves para analizar el conflicto social en el período: perseguir, aprehender y castigar a aquellos elementos del bajo pueblo que transgredan "las leyes ineludibles de la moral social". Similar política se adoptó respecto de los denominados chincheles, mezclas de fondas, tabernas y prostíbulos, que pululaban en el Iquique de la década de 1870. El prefecto Tizón escribía al subprefecto y al comisario de policía en octubre de 1875 una orden tajante:

En esta prefectura, se han recibido informes de personas fidedignas y aún por la prensa se han denunciado los abusos y desordenes que con frecuencia se repiten en algunas casas de particulares establecidas en este lugar bajo la denominación de 'Chincheles' y que son unos verdaderos focos de corrupción y de amenaza a la moral pública y a la sociedad (...) por ningún motivo se permitirá la escistencia de esos establecimientos y que personalmente Ud. sumándosele el comisario de policía, ronde toda la población a distintas horas de la noche vijilando el exacto cumplimiento de esta disposición en imponiendo severas penas a las contraventoras. (FPT, vol. 16, f. 662, 1875)

En marzo del año siguiente, la prensa acusó la persistencia clandestina de algunos de estos locales ante lo cual el prefecto envió otro comunicado al comisario de policía y a sus subalternos en el que amenazaba que incurrían en una gravísima irresponsabilidad si es que podía comprobarse la existencia de siquiera uno de estos establecimientos. El comisario, Lizardo Benjamín Novoa, un militar de Lima, replicó en un tono comunicando que estaba al tanto y que no perdía de vista algunas casas, aparentemente legales, donde se reunían grupos pequeños de mujeres a cantar y bailar. El comisario le pedía paciencia al prefecto señalando: "no es posible cortar de raíz y en tan poco tiempo una costumbre tolerada y admitida en la ciudad por tantos años" (FPT, vol.16, f. 572, 1875). La prefectura ordenó redadas que resultaron en clausuras de locales y detenciones de chincheleras y bailarinas.

El año anterior ya se había ordenado la clausura de los chincheles más conflictivos y la detención de quienes los regentasen. La Guardia Civil daba cuenta de las siguientes detenidas un día 7 de septiembre de 1874: Valeriana Morales, Mercedes Celaya y Micaela Marín (FPT, vol. 125, 1874), todas chilenas y por orden del subprefecto. Las dos primeras aparecían señaladas como chincheleras y la tercera sin ocupación. En ese mismo año fue detenida en dos oportunidades, Carmen Vila, chilena, por escandalosa, de oficio bailarina. Este cargo estaba asociado eventualmente a la ebriedad, el pleito o el festejo a deshoras. Estas chincheleras, cantoras, sin oficio y bailarinas constituían una pequeña muestra de la transgresión femenina asociada a la bohemia y la prostitución.

Los chincheles volverían a aparecer en los desvelos de las autoridades peruanas en más de una ocasión. A pesar de la guerra permanente de la prefectura, jamás se extinguieron, 
siendo los predecesores de las "casas de tolerancia" del período chileno. De este modo, la prostitución fue uno de los tantos factores de conflicto, elemento común a ciudades portuarias, industriales y comerciales de predominio masculino como fue el Iquique de inicios a principios del ciclo de expansión del salitre. El problema de las chincheleras, cantoras y bailarinas nos remite a una temática novedosa, que es la presencia femenina en la temprana migración peonal. Como señalamos en la Tabla $\mathrm{N}^{\circ} 5$, una amplia mayoría de las detenidas practicaba el rudimentario trabajo de ser lavanderas. Eran preferentemente chilenas, seguidas de peruanas y bolivianas. Otro considerable pero menor número de mujeres se dedicaba al trabajo textil: principalmente eran costureras que realizaban toda serie de remedos sencillos. Había una minoría de modistas, cuya labor de confección era más calificada. Detectamos también escenas de violencia y desorden en las calles, donde participó el elemento peonal femenino. En febrero de 1877, Filomena Donaides, de 17 años, chilena, lavandera, soltera, acompañada de Nicolás Taiba, de 18 años, chileno, vendedor de frutas, soltero, fueron detenidos por romperle la cabeza a don Eudoro Marquesado, hermano del salitrero y vicepresidente del Concejo Departamental, Eulogio Marquesado, miembro de una de las familias más ricas e importantes de la provincia (FPT, vol. 77, 1877).

Documentos de la prefectura de la época dan cuenta de algunos casos que ilustran la dura vida que les tocó llevar a estas mujeres. En marzo de 1877, el cónsul chileno enviaba una solicitud al subprefecto, exponiendo lo siguiente:

El portador de este acompaña a la muchacha Matilde Baraona [sic], de nacionalidad chilena, huérfana de padre i madre i que ha buscado asilo en este consulado a consecuencia del maltrato que recibe de sus patrones don Diego Arévalo i señora. Estimaría que Ud. hiciera colocar en una casa respetable a la mencionada Matilde i a disposición de este consulado. (FPT, vol. 77, sin fojas, 18 de marzo de 1877)

La situación que da origen a la intervención del cónsul nos habla de una vida de precariedad y desprotección. El caso de Matilde Baraona y de otros adolescentes huérfanos chilenos detectados en documentos revisados, nos remite a la curiosa posibilidad de migrar que tuvieron huérfanos y adolescentes pobres en el Chile de mediados del siglo XIX (Rojas, 2016).

La principal respuesta de las autoridades frente al crecimiento de la población, y particularmente de sectores populares en formación, consistió en el reforzamiento continuo del cuerpo policial de la ciudad. La Guardia Civil fue uno de los protagonistas de este conflicto social. La creación de este organismo remite a la fusión de cuerpos policiales menores, en diciembre de 1873, por orden del presidente Manuel Pardo, en su proyecto de reforzar el orden público en pro del desarrollo económico y de la estabilidad institucional del país. La reforma se llevó a cabo en todo el Perú en los 
primeros meses de 1874. Una orden del prefecto Amaro Tizón a su subalterno, con fecha 31 de marzo de 1874, señala lo siguiente:

Para conservar la disciplina y la moralidad del cuerpo de celadores de esta provincia, que desde el día de mañana quedará organizada como Guardias Civiles, institución que la deben formar individuos de conducta intachable, esta prefectura dispone que sean dados de baja los celadores Luis Basurco, Pantaleón Carrasco y Luis Guillermo y Guillermo Aliaga, que cometieron graves y escandalosas faltas en las calles publicas el día 22 del actual, manifestándose con semejante conducta indigna de pertenecer al mencionado cuerpo de guardias; y siendo necesario reemplazarlos con personas aptas, disponga Ud. sean dados de alta Abelardo Morales, Vicente Chaves y Pío García así mismo Alejandro Molinas en la vacante del celador que desertó en el Callao. Para que los celadores dados de baja de la columna puedan dedicarse al trabajo para procurar honradamente su subsistencia disponga Ud. sean remitidos al canchón "Las Mercedes" de propiedad del Estado que corre a cargo del presidente de la comisión agrícola del Tamarugal coronel D. Miguel Valleriestra que ha ofrecido abonarles un salario proporcional a su trabajo. (FPT, vol. 16, ff. 131-132).

Este documento contiene una serie de elementos interesantes. Reitera ideas fuerza del período como la disciplina y la moralidad, a la vez que introduce un elemento que será recurrente en las lógicas de las élites para con el mundo popular. El trabajo, en tanto castigo como medio rehabilitador del sujeto, constituía una fuente práctica de manutención de los sancionados, factores todos debatidos profusamente en la teoría penal y jurídica del siglo XIX (Rusche y Kirchheimer, 1984). Los canchones aludidos en el documento correspondían a haciendas de propiedad fiscal, ubicadas al interior de la provincia en tal período. El cuartel de El Morro fue construido a fines de1874, financiado por el Gobierno y por el comercio de la ciudad, los que erogaron 700 soles voluntariamente para tal fin. Esta dinámica sería recurrente en el período estudiado e incluso bajo soberanía chilena.

Las élites económicas de la provincia, desde el mediano comerciante hasta el gran capitalista, contribuían periódicamente con los gastos de la Policía, al ser el orden público esencial para la acumulación y reproducción del capital. En este período, a partir de 1874, “cuartel” y "cárcel” fueron sinónimos. Un presupuesto para reparar los daños sufridos con motivo del terremoto de mayo de 1877 nos describe someramente el edificio que ocupaba la Policía: paredes de cinco metros de altura, dos calabozos, uno para cada sexo, paredes constituidas por dos caras de calamina rellenas de conchuela - "para mejor seguridad, tanto de los habitantes, como [para resguardo] de incendio" (FPT, vol. 79) - y con techo de pino oregón.

Asimismo, el cuartel de Gendarmes también cumplió dicha función, pero se lo menciona con menor frecuencia en los documentos consultados. Una cárcel en condiciones, institución propia del orden social moderno, fue un anhelo jamás satisfecho por las autoridades peruanas de la provincia. El cuartel de la Guardia Civil tendía al hacinamiento, 
a la falta de aseo y, en el período estudiado, fue escenario de numerosos hechos de corrupción e indisciplina. La prisión de la excapital de la provincia, el pueblo de San Lorenzo de Tarapacá, no era alternativa, dado que sus dimensiones eran menores y su estado más deplorable que las cárceles iquiqueñas. Uno de los males endémicos del cuartel de la Guardia Civil eran las constantes fugas y la introducción de armas blancas y licor por parte de los detenidos, con las sospechas de complicidad por parte de algunos guardianes. Estas irregularidades también tenían lugar en la otra "cárcel" de la ciudad, el cuartel de gendarmería. En agosto de 1875, el comandante de dicho cuerpo señalaba que:

El comandante de la expresada da parte a Ud. que habiéndome hecho cargo de la guardia ordene al alcaide que se registrara las camas de los presos donde suelen tener licor y armas ofensivas, y como en la guardia pasada encontré a varios presos embriagados. Tomando esta precaución dispuse que alcaide no se moviera del local, más en cuanto pudo hacer uso de su libertad ha abandonado su puesto llevándose consigo la llave del calabozo. (FPT, vol. 77, sin fojas, 19 de agosto de 1875)

Ahora bien, ¿qué hacer con los detenidos? Como señalan documentos de la prefectura, falencias del poder judicial en la provincia provocaban una permanente congestión en las cárceles de la ciudad. Una solución adecuada era ponerlos a trabajar. El manejo de las basuras y el riesgo de epidemias fue un desafío permanente en el Iquique salitrero, tanto bajo la administración peruana como bajo la chilena. Los malos hábitos de gran parte de la población, la permanente desobediencia a las ordenanzas municipales y la carencia de un sistema eficiente de retiro de basuras y aguas servidas formaban un complejo problema. Cada cierto tiempo el Concejo Departamental debía inspeccionar vivienda por vivienda, especialmente las más pobres, para cerciorarse de que sus habitantes cumplieran con la prohibición de improvisar letrinas en agujeros en el suelo, o bien, formaran depósitos ilegales de basuras (FPT, vol. 87). En abril de 1873, el médico de la ciudad, Dr. Ego Aguirre, enviaba el siguiente informe a la prefectura respecto del estado sanitario de la población:

¿Por qué no desaparece la viruela y lejos de eso se propaga más y más? En primer lugar por el frecuente tráfico marítimo de pasajeros. En segundo lugar por el excesivo calor del verano, y en tercer lugar por la falta de aseo público y privado. Este puerto lejos de presentar el aspecto de una población rica y llena de recursos, es inmundo: cada techo, cada corral es un muladar; en la calle se tropieza a cada rato con inmundicias, los animales en plena putrefacción están esparcidos hasta en las calles más centrales. Allí donde muere un perro, un burro o una mula, allí se queda, allí se corrompe, allí se deshace hasta convertirse en polvo. (FPT, vol. 87, sin fojas, 23 de abril de 1873)

Las autoridades peruanas reforzaron el escaso personal que atendía el aseo de la ciudad con presos debidamente vigilados por guardianes. Un documento de mayo de 1876 nos indica cómo funcionaba este sistema. Los presos eran trasladados en carretas a labores de 
aseo "de las basuras y demás inmundicias que exist[ía]n aglomeradas en la parte norte de esta población (FPT, vol. 121, sin fojas, 30 de mayo de 1876), refiriéndose al Colorado, basural de la población. Tanto las carretas como los jornales de los presos corrían a cuenta de la alcaldía del Honorable Concejo Provincial, la municipalidad en la Ley Orgánica de Municipalidades de abril de 1873. También se utilizaban a los presos en diversas obras públicas, como era el caso de la construcción de la iglesia. Terremotos e incendios dieron cuenta de las iglesias que tuvo la ciudad hasta la construcción de la actual catedral.

En 1875, presos que trabajaban en la construcción de una capilla provisional se fugaron de las obras, aprovechando un descuido de los guardianes que los vigilaban (FPT, vol. 77). El intento de convertir a los presos de la ciudad en fuerza de trabajo remunerada se veía frustrado ante las falencias del cuerpo policial y la permanente rebeldía de los reos. En mayo de 1876, año en que recrudeció el problema del bandidaje en la pampa, el comisario de policía de La Noria remitía a Iquique al chileno José Valdivia, sin oficio conocido, capturado en los alrededores del poblado con herramientas para abrir puertas y soles falsos. Valdivia venía de fugarse hacía pocos días, junto con otros acusados de bandidaje, del cuartel de la Guardia Civil de Iquique.

No solo de bandidos, vagos y del aseo debían preocuparse los policías. El servicio de alumbrado público fue un problema para las autoridades de la ciudad. El principal escollo era la falta de fondos para cancelarlo. Los vecinos de la ciudad reclamaban la protección de la luz nocturna contra los peligros que podría traer la oscuridad; sin embargo, se mostraban reacios al momento de contribuir con su financiamiento. El Honorable Concejo Provincial siempre se veía endeudado y corto de fondos por este motivo. Hacia 1879, cada vecino debía, en teoría, dar un aporte a la municipalidad por este concepto, obligación con frecuencia evadida, situación que generó déficits en el erario, pleitos con la empresa y períodos de oscuridad en la ciudad (Donoso, 2007). Hasta el último año de la soberanía peruana, las autoridades del puerto lamentaron la ausencia de una cárcel en toda regla. En enero de 1879, poco antes del inicio de la guerra, el prefecto manifestaba al Honorable Concejo Provincial:

La provincia de Iquique, la más rica de todo el territorio nacional, es sin duda alguna, la que debería tener más satisfactoriamente servidos sus intereses locales; pero no sucede así por desgracia, como Ud. y los demás miembros del $\mathrm{H}$. Concejo lo conocen. Haciendo abstracción por ahora de muchas otras cosas me limito a llamar la atención de Ud. sobre la carencia absoluta en que se encuentra esta provincia de un local que pueda merecer el nombre de cárcel, siendo, como es sumamente necesario tener un lugar de seguridad para los malhechores que en esta provincia abundan desgraciadamente. El local que, en esta provincia, lleva el nombre de cárcel, es tan inseguro, que constantemente la sociedad está amenazada del peligro, de que los criminales, entre los que existen algunos tristemente célebres, rompan sus cerraduras y se entreguen a la perpetración de nuevos crímenes. Recomiendo a Ud. y a la honorable corporación que preside, que 
preferentemente se ocupe de esta obra indispensable, que podría construirse sobre 'la Isla'. (FPT, vol. 68, sin fojas, 18 de enero de 1879)

Fue la administración chilena la que retomó la idea de utilizar la isla Serrano como presidio, mientras se construía una cárcel y un cuartel de policía acorde que contara con mejores condiciones para su debido funcionamiento. Los protagonistas del conflicto y el espacio urbano

Uno de los principales objetivos de esta investigación ha sido rescatar al sujeto popular del pasado, en particular a los trabajadores chilenos, cuyas experiencias de vida contienen una serie de elementos de interés. Más allá de los cuadros estadísticos ya presentados, nos surge una serie de preguntas: ¿quiénes eran los actores del conflicto social?, ¿en dónde vivían?, ¿qué clase de sociabilidad establecieron con otros sujetos?, ¿cómo transcurrían sus vidas durante los años en que se los mencionan en los documentos históricos revisados?

Un expediente criminal de 1877 expone una interesante historia. La noche del 16 de julio del mencionado año fue apresado José Vallejos (Fondo del Juzgado del Crimen de Iquique, 1877, en adelante FJCI). Se encontraba este arriba del techo de la casa del distinguido relojero Salomón Phillips, quien se percató de la presencia de ruidos en el tejado de su vivienda-taller a medianoche. Vallejos fue reducido por Phillips y vecinos, y entregado a la Guardia Civil. Al ser interrogado por el juez, Vallejos declaró ser chileno, zapatero de oficio, tener 20 años, católico de religión y llegado hacía un mes a Iquique. Su primera residencia había sido en Chanabaya o Puerto Inglés, donde estuvo un breve período trabajando, sin especificar en qué.

Los pequeños puertos y covaderas del litoral, al sur de Iquique, dieron trabajo a numerosos inmigrantes chilenos como Vallejos, quienes probablemente vinieron a la ciudad tras los graves daños que dejó en el litoral el terremoto y maremoto de mayo de 1877. Alojaba, sin especificar, en los emergentes barrios obreros del sector norte de la ciudad, cerca de la estación del ferrocarril Días antes de ser apresado, había estado detenido, acusado por abigeato, en los calabozos de la Guardia Civil, de los cuales se fugó. El abigeato consistió en intentar robar una mula de la panadería del italiano Clemente Daor, ubicada en calle Bolívar. El relojero acusaba la pérdida de cinco relojes de oro y plata. Sin embargo, al momento de ser capturado en el techo de la casa, Vallejos no tenía en su propiedad los relojes. ¿Cuál fue la teoría de la acusación del querellante? Seguramente, Vallejos estaba con un cómplice a quien le entregó los relojes momentos antes de su captura. No obstante, estos fueron rápidamente reducidos en las casas de empeño de la ciudad.

Se levantaron entonces sospechas contra otro peón chileno con quien Vallejos había trabajado en Puerto Inglés y se había venido con él a Iquique. Los dueños de estas casas de empeño, entre quienes identificamos a dos comerciantes italianos, eran vistos con desconfianza por las autoridades, al creérseles reducidores de especies robadas, razón por la cual debían constantemente entregar inventarios para contrastarlos con las denuncias de objetos robados. Los relojes jamás aparecieron y los italianos sospechosos de haberlos 
recibido negaron toda relación con el crimen. El caso quedó sin resolver y probablemente Vallejos pasó a engrosar la lista de peones chilenos detenidos al ser encontrados en las inmediaciones de robos o sorprendidos vagando por las calles de la ciudad sin trabajo formal.

Este caso nos habla de una incipiente segregación socioespacial de la ciudad: los comerciantes europeos, élites de la ciudad, tenían sus propiedades en puntos céntricos, mientras, al norte, se fueron configurando "callejones sin nombre" poblados por individuos como Vallejos. Por otra parte, las élites citadinas, a las que pertenecían Salomón Phillips o Clemente Daor, observaban con recelo y desconfianza a estos peones itinerantes.

Hemos identificado algunas localizaciones en el espacio urbano en donde habitaban emergentes sectores populares. Si el Iquique chileno fue el Iquique de los conventillos, el Iquique peruano fue el Iquique de los ranchos: pequeñas construcciones de material ligero, ubicados en los límites de la ciudad con las pampas circundantes. Su construcción no se ajustaba a ordenanzas ni a medidas higiénicas de ningún tipo. Hemos distribuido geográficamente algunas locaciones al vincularlas a recintos o edificios de cuya ubicación tenemos certeza. Un documento de 1876 señalaba:

En la madrugada de ayer, con intervalo de una hora poco más menos, tuvieron lugar en este puerto dos amagos de incendio, en un rancho que se halla a la espalda de la Iglesia Matriz y que es habitado por gente del pueblo. Descuido y embriaguez de parte de sus moradores motivó la inflamación de algunas soleras que servían de muebles a esa pobre gente; pero la actividad desplegada por la policía evitó el desarrollo del fuego rompiendo trapos, esteras y demás materias combustibles que se encontraban en el rancho. (FPT, vol. 98, sin fojas, 1 de marzo de 1876)

La iglesia mencionada se ubicaba en el mismo sector donde se emplaza la actual catedral de la ciudad. Esto nos permite situar esta vivienda en el sector norte de la ciudad y vislumbrar un paisaje de ranchos en terrenos comprendidos entre la Estación del Ferrocarril y lo que hoy es la Plaza de la Catedral. En el discurso de las autoridades, la pobreza y el vicio crearon el ambiente propicio para el fuego, un peligro público que fue, en esta ocasión, exitosamente reprimido por la policía en un allanamiento que destruyó las pocas posesiones materiales de los habitantes del rancho. Al respecto, encontramos más casos que refuerzan este temprano patrón de asentamiento de los trabajadores migrantes en la ciudad. En diciembre de 1878, Manuel García, jornalero, apuñaló varias veces a José Callejas, fundidor. Ambos jóvenes, chilenos y solteros, compartían una habitación o casa en la "calle de la estación" o "calle que hay detrás de la estación". Callejas quedó gravemente herido. (FJCI, 1878, Caja 584, expediente $\mathrm{N}^{\circ} 20$ )

Una vez iniciadas las hostilidades en abril de 1879, Lima dispuso la expulsión de los chilenos residentes en el territorio nacional. Tarapacá se encontraba ampliamente poblado por individuos de esta nacionalidad. Numerosos chilenos fueron perseguidos, encarcelados 
o embarcados de vuelta a su país (Donoso, 2004). Sin embargo, el proceso de gestación de amplios sectores populares urbanos era irreversible. Esto quedó demostrado en las preocupaciones y medidas de seguridad adoptadas por las élites residentes no-beligerantes durante el breve vacío de poder, resultante de la retirada de las autoridades peruanas en la mañana del 22 de noviembre de 1879 (Bulnes, 1955).

\section{Conclusiones}

A lo largo de la década de 1870 se desarrolló en Iquique una compleja sociedad urbana, compuesta por elementos venidos de todo el mundo. La llegada de estos nuevos actores a vivir a la ciudad se caracterizó por su vínculo con la marginalidad y la pobreza, y por el permanente conflicto que sostuvieron con las élites y autoridades del puerto. El objeto de estudio de este artículo fueron los sectores populares urbanos, con énfasis en el elemento chileno, sus rebeldías primarias y su tensa relación con las autoridades peruanas.

Esta historia vista "desde abajo" no puede escribirse sin considerar las estructuras globales del período y el conjunto de individuos que conformaban las denominadas élites. Estas contradicciones manifiestas entre ese mundo popular y las élites contribuyeron a dar forma a la ciudad de Iquique, generando ordenanzas, cuerpos de policías y creando la necesidad de servicios como el retiro de basuras y el alumbrado público.

El objetivo implícito por parte de las élites urbanas y la administración de la época fue vigilar y controlar el espacio, a la vez que convertir al puerto en una ciudad funcional a la reproducción y acumulación del capital en una década compleja, como fue la de 1870. Los problemas endémicos de la administración pública de la provincia y la ciudad impidieron la consolidación de un aparato represivo efectivo, consolidación que hubiese significado al menos la construcción de una cárcel que contara con las condiciones para suplir los deficientes calabozos de los cuarteles existentes.

El conflicto histórico que significó disciplinar al peonaje y consolidar la proletarización, y el proyecto capitalista en el espacio urbano de Iquique continuó a lo largo del ciclo de expansión del salitre. En ese sentido, las rebeldías y las respuestas a ellas, de las que da cuenta este estudio, constituyen un lejano antecedente de las modernas luchas obreras de principios del siglo XX.

Los elementos presentados en la presente investigación también configuran una temprana historia social, con foco en las clases bajas de la ciudad de Iquique y de sus dinámicas de desarrollo sociohistórico, que trascendieron la guerra y el cambio de soberanía. 


\section{Referencias bibliográficas}

Archivo Nacional, Fondo de la Prefectura de Tarapacá (FPT). Vols. 16, 68, 77, 79, 87, 98, 121.

Archivo Nacional, Fondo de la Intendencia de Tarapacá (ARNIT). Vol. 592, pp.7, 9, $15,30,88,91,123,129,150,151$.

Archivo del Obispado de Iquique (AOI). Libro $\mathrm{N}^{\circ} 2$ de Defunciones 1857-1875, Libro $\mathrm{N}^{\circ}$ 3 de Defunciones 1870-1873 y Libro $\mathrm{N}^{\circ} 4$ de Defunciones 1873-1878. Libro $\mathrm{N}^{\circ} 4$ de bautismos 1870-1872, Libro $\mathrm{N}^{\circ} 5$ de bautismos 1872-1875 y Libro $\mathrm{N}^{\circ} 6$ de bautismos 1875-1876.

Bengoa, J. (1990). Haciendas y campesinos. Historia social de la agricultura chilena. Tomo II. Santiago: Ediciones Sur.

Billinghurst, G. (1889). Los capitales salitreros de Tarapacá. Santiago: Imprenta El Progreso.

Bourdieu, P. (2001). Poder, derecho y clases sociales. Bilbao: Desclee Editorial.

Brito, A. (2005). De mujer independiente a madre, de peón a padre proveedor. La construcción de identidades de género en la sociedad popular chilena 1880-1930. Concepción: Ediciones Escaparate.

Bulnes, G. (1955). La Guerra del Pacífico Vol.1. Santiago: Editorial del Pacífico.

Caimari, L. (2015). La "cuestión criminal" y los historiadores en America Latina. En D. Palma, Delincuentes, policías y justicias en América Latina. Siglos XIX y XX (pp. 491-507). Santiago: Editorial Universidad Alberto Hurtado.

Crozier, R. (1997). El salitre hasta la Guerra del Pacifico: una revisión. Historia, 30, 53-126.

Donoso, C. (2003a). El puerto de Iquique bajo administración peruana. Historia, 36, 123-158.

Donoso, C. (2003b). Obreros, industriales y cónsules extranjeros en Iquique durante los años de la administración peruana (1830-1879). Si Somos Americanos. Revista de Estudios Transfronterizos, 5(4), 83-106.

Donoso, C. (2004). El comienzo del bloqueo de Iquique y la situación de los chilenos en Tarapacá a traves de la correspondencia del cónsul Antonio Solari Millas. Revista de Ciencias Sociales, 14, 105-176.

Donoso, C. (2007). Estado y sociedad en Iquique bajo administración peruana 1821-1872 (tesis doctoral para optar al grado en Historia, mención Historia de Chile). Facultad de Filosofía y Humanidades, Departamento de Ciencias Históricas, Universidad de Chile, Santiago.

Donoso, C. (2011). Los ferrocarriles salitreros como factor de desarrollo temprano en Tarapacá. Historia 396, 1(1), 51-76.

Ealham, C. (2005). La lucha por Barcelona. Madrid: Alianza Editorial. 
Filgueira, D. (2015). Historia de las Compañías de Bomberos de Iquique y datos refrentes a las mismas hasta el año 1888. Iquique: Editorial Pino Oregón.

Fondo del Juzgado del Crimen de Iquique (1877). Caja 650, expediente $\mathrm{N}^{\circ} 16$.

Fondo del Juzgado del Crimen de Iquique (1878). Caja 584, expediente $\mathrm{N}^{\circ} 20$.

Godoy, M. (2003). La "Aduana de hombres": discusión en torno a una propuesta de control popular (1868·1872). Histórica, 1(27), 141-168.

Godoy, M. (2017). Mundo minero y sociabilidad popular en el Norte Chico. Chile, 17801900. Santiago: Ediciones Universidad Academia de Humanismo Cristiano.

González, S. (2000). Guillermo Billinghurst Angulo: una biografía regional. Revista de Ciencias Sociales, 9(10), 5-24.

González, S. (2002). Hombres y mujeres de la pampa salitrera. Tarapacá durante el ciclo de expansión del salitre. Santiago: RIL-Universidad Arturo Prat-LOM Ediciones.

González, S. (2012). La resistencia de los tarapaqueños al monopolio del salitre durante el gobierno de Manuel Pardo, desde el estanco a la expropiación (1872-1876). Chungará, Revista de Antropología Chilena, 44(1), 101-104.

González, S. (2014). Las inflexiones de inicio y tÉrmino del ciclo de expansión del salitre (1872-1879). Una crÍtica al nacionalismo metodológico. Dialogo Andino, 45, 3949.

González, S. (2016). Matamunqui: El ciclo de expansión del nitrato de Chile. La sociedad pampina y su industria. Santiago: RIL Editores.

González, S. y Bravo, P. (1994). Iquique y la pampa. Relaciones de corsarios, viajeros e investigadores (1500-1930). Antofagasta: Taller de Estudios Regionales, Universidad José Santos Ossa.

Grez, S. (2000). Transición en las formas de lucha: motines peonales y huelgas obreras en Chile (1891-1907). Historia, 33, 141-225.

Hobsbawm, E. (1998). La era del capital. Buenos Aires: Planeta.

Illanes, M. A. (1990). Azote, salario y ley. Disciplinamiento de la mano de obra en la mineria de Atacama (1817-1850). Proposiciones, 19, 90-122.

Larraín, P. (2002). La presencia de la mujer chilena en la Guerra del Pacífico. Santiago: Ediciones Universidad Gabriela Mistral.

Lefebvre, H. (2013). La producción del espacio. Madrid: Capitán Swing Libros.

Mc Evoy, C. (1994). Un proyecto nacional en el siglo XIX: Manuel Pardo y su visión del Perú. Lima: Fondo Editorial Pontificia Universidad Católica del Perú.

Pinto, J. (1998). Trabajos y rebeldías en la pampa salitrera. Santiago: Editorial USACH. 
Pinto, J.y Ortega, L. (1990). Expansión minera y desarrollo industrial: un caso de crecimiento asociado (1850-1914). Santiago: Departamento de Historia de la Universidad de Chile.

Pinto, J.y Valdivia, V. (1997). Peones chilenos en tierras bolivianas: la presencia laboral chilena en Antofagasta (1840-1879). En R. Barragán y S. Qayum, El siglo XIX: Bolivia y América Latina (pp. 171-201). Lima: Institut Français d'Études Andines.

Pinto, J., y Valdivia, V. (2009). ¿Chilenos todos? La construcción social de la nación (1810-1840). Santiago: LOM Ediciones.

Registro Oficial (27 de enero de 1870). Año I, N 12, Iquique.

Rojas, J. (2016). Historia de la infancia en Chile republicano. Santiago: Ediciones Junji.

Romero, L. A. (1990). Los sectores populares urbanos como sujeto historico. Proposiciones, 19, 268-278.

Romero, L. A. (2007). ¿Que hacer con los pobres? Elites y sectores populares en Santiago de Chile 1840-1895. Santiago: Ariadna Ediciones.

Rusche, G.y Kirchheimer, O. (1984). Pena y estructural social. Bogotá: Temis.

Salazar, G. (2000). Labradores, peones y proletarios. Santiago: LOM Ediciones.

Salazar, G.y Pinto, J. (1999). Historia contemporánea de Chile II. Actores, identidad y movimiento. Santiago: LOM Ediciones.

Scobie, J. R. (1991). El crecimiento de las ciudades latinoamericanas 1870-1930. En L. Bethell, Historias de America Latina Vol.VII (pp. 202-230). Barcelona : Editorial Crítica.

Thompson, E. P. (1989). La formación de la clase obrera en Inglaterra. Barcelona: Editorial Crítica.

Torres, J. A. (2017). Familias fundadoras de Pica y Matilla (1590-2015). Vol II. Arica: Ediciones Universidad de Tarapacá.

Villalobos, R. S. (1979). La economía de un desierto. Santiago: Ediciones Nueva Universidad.

Wright Mills, C. (1987). La élite del poder. México D.F.: Fondo de Cultura Económica. 